\title{
A Rare Differential Diagnosis for Acute Abdominal Pain- Torsion Lipoma of Greater Omentum
}

MUNIKUMAR AMBURU1', MOHAMMED ZAKARIYA ABDUL REZAK², LOGANATHAN MANNU ACHARI ${ }^{3}$, NATARAJAN RAMALINGAM ${ }^{4}$, KARUNANITHI RAMAIAH ${ }^{5}$

\begin{abstract}
Lipoma is a benign neoplasm arising from yellow fat. Often it can be hyperplasia or combination of neoplasm and hyperplasia. It is composed of mature adipocytes and uniform nuclei that are identical to those seen in normal adult fat. It is called as universal tumour/ubiquitous tumour as it can occur anywhere in the body outside of brain. It can be localised (encapsulated) or diffuse (nonencapsulated). It can occur in sites like subcutaneous, subfascial, intramuscular, intermuscular in anterior abdominal wall, paraosteal, submucosal, subserosal sites. Here, a case of torsion of the lipoma in the greater omentum is reported presenting as acute abdomen. This eight-year-old girl presented with symptoms of right iliac fossa pain, signs of localised peritonitis and right psoas irritation. Appendicular mass/abscess was considered on clinical examination. The radiological evaluation ruled out appendicular pathology and an ovarian pathology possibly a torted ovary was suspected. During surgical exploration, a tumour of greater omentum was identified and resected. This rarity of the differential diagnosis for a right lliac fossa mass is highlighted herewith.
\end{abstract}

Keywords: Adnexal mass, Distal greater omentectomy, Panniculitis, Right lliac fossa mass

\section{CASE REPORT}

An eight-year-old girl presented to outpatient clinic with a limp on her right hip. She had pain in right lower abdomen since three days which was insidious in onset, gradually progressing in severity. Pain was aggravated on walking. There was no history of fever, vomiting, and burning micturition. No similar complaints in the past. On examination, right lower quadrant moved relatively less when compared to other quadrants. The right iliac fossa was tender and involuntary guarding was present. Rovsing's sign was negative. A clinical working diagnosis of appendicular mass with possibility of abscess formation was made. Other differential diagnoses of psoas abscess, lleoceacal tuberculosis and torsion of the right ovarian cyst was considered. Ultrasound of the abdomen showed features of right adnexal mass. CT abdomen showed features of a fat density lesion in right adnexa with adjacent inflammation (adnexal mass)possibility of torsion in right ovarian dermoid [Table/Fig-1].

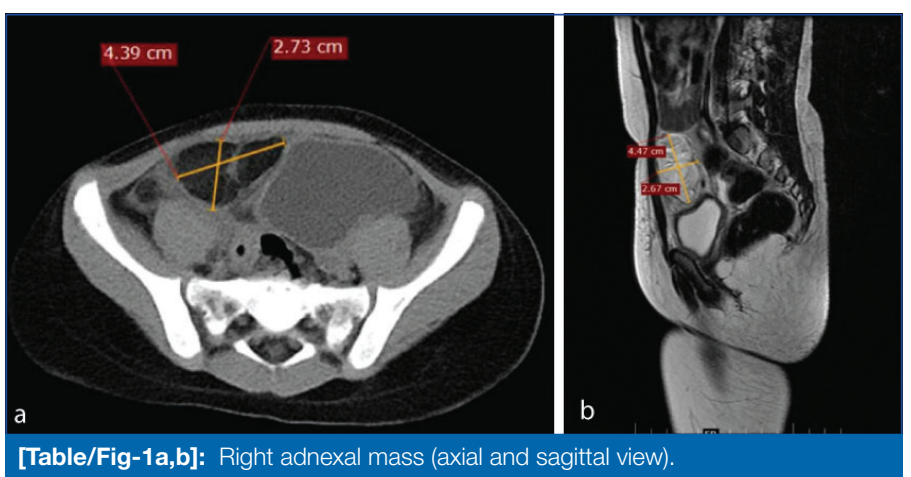

A laparotomy was performed through a pfannenstiel incision. Intraoperatively, both the ovaries and tubes was found to be normal [Table/Fig-2]. An omental tumour with torsion of size $8 \times 6 \mathrm{~cm}$ [Table/Fig-3] was found adherent to the right lateral pelvic wall and posteriorly to the psoas.

A distal greater omentectomy was performed. Histopathological examination revealed a lipoma with changes of torsion and panniculitis [Table/Fig-4]. A final diagnosis of torsion of omental

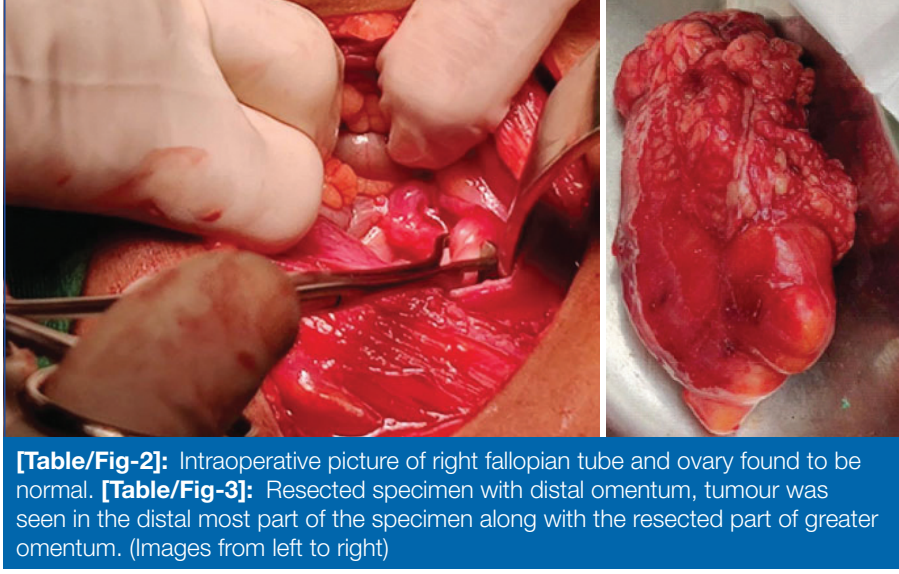

lipoma with panniculitis was made. The postoperative period was uneventful. The patient was followed-up at two weeks and later at two months. There were no postoperative complications. As the tumour was benign, no further follow-ups were advised.

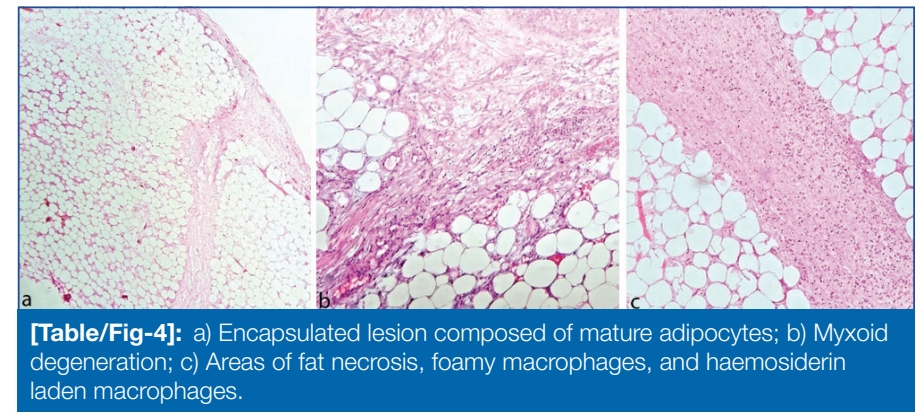

\section{DISCUSSION}

Lipomas are most common adipose tissue tumour mostly located in the subcutaneous tissue. Intra-abdominal lipomas most commonly arise from mesentry, omentum, and epiploic appendices due to the presence of ample amount of adipose tissue in them. The various reported incidence of greater omental torsion is in the range of $0.0016-0.37 \%$ and is the cause in $1.1 \%$ of cases 
of all abdominal pains [1]. Men between 40-50 years are more commonly affected [1].

Tumours of the greater omentum originate from its constituentsfat tissues, blood and lymphatic vessels present as leiomyoma, leiomyosarcoma, fibroma, fibrosarcoma, haemangiopericytoma, lipoma, liposarcoma [2]. The exact incidence of torsion of the omental lipoma is not clear as these are rarely occurring tumours and torsion in the tumours is rarer.

For unknown reasons, omental lipomas appear to be more commonly reported in paediatric age groups. A $1.5 \mathrm{~kg}$ tumour in a nine-monthold infant and a $1.82 \mathrm{~kg}$ giant lipoma in a 11-month-old infant was reported by Srinivasan KG et al., and Luo X et al., respectively [3,4]. The specimen weighed about $500 \mathrm{~g}$ after excision in present case. The main presentation is due to the development of panniculitis and resultant adhesion to the abdominal wall and psoas muscle.

Multiple case reports of omental lipomas have been found in literature, but most of these cases are reported only after a complication of the tumour or from the pressure effects in case of giant lipomas. Of all these cases (few cited below) in the literature presented with complications, none of the cases presented with torsion or panniculitis causing adhesion to the abdominal wall [5-11]. In this case, the tumour was adherent to the right posterolateral abdominal wall on to the psoas muscle causing psoas irritation and hence mimicking psoas abscess or appendicular abscess clinically.

Large omental lipomas can undergo torsion and present as acute abdomen. Torsion of omental lipoma occurs due to twisting of the pedicle of the omentum along its long axis resulting in the vascular compromise which leads to severe abdominal pain. It was first described in the literature in 1858, by deMarcetti while the first report of primary omental torsion came from Eitel in 1899 [5].

Omental lipomas are generally asymptomatic and are usually incidentally encountered. Most of the omental lipomas can be picked up by the USG [6]. An interesting clinical presentation of a giant omental lipoma was reported by Chandra $\mathrm{H}$ et al., in the year 1941, where this benign tumour was misinterpreted as a full term pregnancy in a 31-year-old female [7]. The patient also had a coincidental amenorrhoea for 10 months, due to reasons unrelated to the tumour.

Giant lipomas can cause pressure symptoms like dyspnoea, orthopnoea. A huge encapsulated greater omental mass of $6.9 \mathrm{~kg}$ causing pressure on the diaphragm has been reported by Sen $D$ et al., which resolved after surgical excision [8].

An instance of deranged liver function test has been reported in a case of giant omental lipoma, which promptly normalised after resection of the tumour has been reported [9]. The cause for deranged liver functions has not been clearly described.

The rare occurrence of these lipoma and varied presentations has led to misdiagnosis often in these situations. Karanikas $M$ et al., reported a case of primary greter omental torsion presenting with right iliac fossa and right scrotal pain and was diagnosed as acute appendicitis [10].

Yang TW et al., published a case of intra-abdominal lipoma in a 67year-old male presenting with acute abdominal pain diagnosed with antimesenteric lipoma of the ileum for which they performed en bloc segmental resection with end to end anastomosis in an attempt to avoid postoperative bowel stricture and to obtain tumour-free margins. Antimesenteric lipomas may undergo torsion and may lead to intestinal obstruction. It is always a diagnostic challenge to diagnose omental lipomas with the non-specific clinical features [11]. A characteristic CT finding of under $60 \mathrm{HU}$ density values of the lesion can be helpful in definitive diagnosis [12]. The rate of recurrence after excision is less than 5\% [13].

\section{CONCLUSION(S)}

Although omental lipomas are rare, it should be considered as one of the differential diagnosis of an intra-abdominal mass. Careful radiological evaluation can pick up the tumour and a surgical excision is advisable even in case of incidental lipomas, as it is thought to develop complications. Due to less published reports, the long-term behaviour of these lesions is not well known. Hence, a long-term follow-up is advisable.

\section{REFERENCES}

[1] Mendoza MF, Gago MRD, Garcia DMC, Muñoz PA, Alonso MD, Noguerales Fraguas $F$, et al. Primary omental torsion as presentation of acute abdomen. Case report. Revista espanola de enfermedades digestivas: Organo oficial de la Sociedad Espanola de Patologia Digestiva. 2016;108(2):105-06.

[2] Ishida $\mathrm{H}$, Ishida J. Primary tumours of the greater omentum. European Radiology. 1998;8(9):1598-601

[3] Srinivasan KG, Gaikwad A, Ritesh K, Ushanandini KP. Giant omental and mesenteric lipoma in an infant. African Journal of Paediatric Surgery: AJPS. 2009;6(1):68-69.

[4] Luo X, Gao W, Zhan J. Giant omental lipoma in children. Journal of Pediatric Surgery. 2005;40(4):734-36.

[5] Dhooghe V, Reynders D, Cools P. Torsion of a bifid omentum as a rare cause of acute abdomen: A case report. Journal of Medical Case Reports. 2016;10(1):289.

[6] Haller JO, Schneider M, Kassner EG, Slovis TL, Perl LJ. Sonographic evaluation of mesenteric and omental masses in children. AJR American Journal of Roentgenology. 1978;130(2):269-74.

[7] Chandra H. Omental Lipoma. The Indian Medical Gazette. 1941;76(7):420-21.

[8] Sen D, Chakrabarti R, Ranjith M, Gulati D. Giant omental lipoma in an elderly female patient. Med J Armed Forces India. 2018;74(4):377-79.

[9] Tan WJ, Chan WH. Giant omental lipoma. Singapore Medical Journal. 2012;53(6):e131-32.

[10] Karanikas M, Kofina K, Boz Ali F, Vamvakerou V, Effraemidou E, Lyratzopoulos N et al. Primary greater omental torsion as a cause of acute abdomen-a rare case report. Journal of Surgical Case Reports. 2018;2018(8):207.

[11] Yang TW, Tsuei YW, Kao CC, Kuo WH, Chen YL, Lin YY. Torsion of a giant antimesenteric. The American Journal of Case Reports. 2017:18:589-92.

[12] Prando A, Wallace S, Marins JL, Pereira RM, de Oliveira ER, Alvarenga M. Sonographic features of benign intraperitoneal lipomatous tumours in childrenReport of 4 cases. Pediatric Radiology. 1990;20(8):571-74.

[13] Hamidi H, Rasouly N, Khpalwak H, Malikzai MO, Faizi AR, Hoshang MM, et al. Childhood giant omental and mesenteric lipoma. Radiology Case Reports. 2016;11(1):41-44.

\section{PARTICULARS OF CONTRIBUTORS:}

1. Postgraduate Trainee, Department of General Surgery, Chettinad Academy of Research and Education, Kelambakkam, Tamil Nadu, India.

2. Assistant Professor, Department of General Surgery, Chettinad Academy of Research and Education, Kelambakkam, Tamil Nadu, India.

3. Professor, Department of General Surgery, Chettinad Academy of Research and Education, Kelambakkam, Tamil Nadu, India.

4. Associate Professor, Department of General Surgery, Chettinad Academy of Research and Education, Chennai, Tamil Nadu, India.

5. Professor, Department of General Surgery, Chettinad Academy of Research and Education, Chennai, Tamil Nadu, India.

NAME, ADDRESS, E-MAIL ID OF THE CORRESPONDING AUTHOR:

Natarajan Ramalingam,

B8, Plaza Court, No. 28, Church Road, Perungudi, Chennai, Tamil Nadu, India. E-mail: surgnutty@gmail.com

\section{AUTHOR DECLARATION:}

- Financial or Other Competing Interests: None

- Was informed consent obtained from the subjects involved in the study? Yes

- For any images presented appropriate consent has been obtained from the subjects. Yes
PLAGIARISM CHECKING METHODS: [Jain Het al.]

- Plagiarism X-checker: Sep 26, 2020

- Manual Googling: Feb 04, 2021

- iThenticate Software: Mar 22, 2021 (18\%)
ETYMOLOGY: Author Origin

Date of Submission: Sep 25, 2020

Date of Peer Review: Dec 23, 2020

Date of Acceptance: Feb 09, 2021

Date of Publishing: Oct 01, 2021 